\title{
Decomposition of the $\beta$ phase at intermediate temperature in $\beta$-metastable Ti-5553 alloy
}

\author{
Morgan Goetz ${ }^{\mathrm{a}, \mathrm{c}}$, Moukrane Dehmas ${ }^{\mathrm{b}}$, Benoît Appolaire ${ }^{\mathrm{a}}$, Elisabeth Aeby-Gautier ${ }^{\mathrm{a}}$, Sandra Andrieu ${ }^{\mathrm{c}}$, \\ Thomas Billot ${ }^{\mathrm{c}}$ \\ ${ }^{a}$ Université de Lorraine - CNRS, IJL, 2 allée André Guinier, 54000 Nancy, France \\ ${ }^{b}$ CIRIMAT, Université de Toulouse, 4 allée Emile Monso, 31030 Toulouse, France \\ ${ }^{c}$ Safran Landing Systems, site de Bidos, 9 rue Guynemer, 64401 Oloron Sainte Marie, France
}

Keywords: Ti-5553 alloy, phase transformation kinetics, STEM-EDX analysis, $\alpha / \beta$ interfaces

\begin{abstract}
$\underline{\text { Abstract }}$
The present contribution focuses on the nature of the $\beta \rightarrow \alpha$ transformation in Ti-5333 alloy at intermediate temperatures. It is indeed still unclear whether this transformation is only controlled by bulk diffusion or whether interfacial kinetics may play a role. To address this issue, we have combined SEM and STEM-EDX to measure the concentrations of Al, Cr, Mo, V and Fe in $\alpha$ intragranular precipitates as well as in the abutting $\beta$ matrix, paying a particular attention to the concentrations at flat interfaces corresponding to the precipitates habit planes. The comparison with Calphad calculations suggests that interfaces are not at equilibrium during the thickening of the plates.
\end{abstract}

\section{Introduction}

$\beta$-metastable titanium alloys combine an excellent strength-to-weight ratio and good formability. Moreover, due to their ability to retain metastable $\beta$ at room temperature after quenching, they offer significant flexibility for designing a large variety of microstructures, resulting from various thermal and/or thermomechanical treatments. In this regard, the $\beta \rightarrow \alpha$ transformation is the most important among the different possible phase transformations. Indeed, $\alpha$ can precipitate on various nucleation sites, adopting different length scales, spatial distributions and morphologies. In order to obtain specific microstructures for some targeted mechanical properties with the relevant heat treatment, one must be able to predict the transformation kinetics, related to the transformation mechanisms.

Several studies have been devoted to the decomposition of $\beta$ during isothermal holdings, with an emphasis on the partitioning of the alloying elements. Enomoto and Yoshida [1] have investigated this partitioning during the formation of proeutectoid $\alpha$ in Ti$\mathrm{X}_{1}-\mathrm{X}_{2}$ alloys $\left(\mathrm{X}_{1}=\mathrm{Al}\right.$ or $\mathrm{V} ; \mathrm{X}_{2}=\mathrm{Cr}$ or $\left.\mathrm{Fe}\right)$ between 500 and $700^{\circ} \mathrm{C}$ by means of quantitative STEM-EDX chemical analysis. They found a fairly good agreement between the measurements and the prediction based on the usual local equilibrium assumption. However, the measurements were not accurate enough to provide a definitive answer. The same problem has been handled by Chen et al. [2] using phase field and DICTRA calculations, assuming once again that local equilibrium holds at the $\alpha / \beta$ interface. Although the order of magnitude of the kinetics appeared realistic, the calculations have not been compared with accurate measurements of the kinetics and of the concentration profiles, such that there is still no clue about the soundness of the local equilibrium assumption for the $\beta \rightarrow \alpha$ transformation in titanium alloys. More recently, atom probe tomography (APT) measurements $\alpha / \alpha$ " microstructures have shown that interface concentrations deviate from local equilibrium at low temperature [3].

To address further the issue of partitioning of alloying elements during the formation of $\alpha$ in Ti-5553, we have carefully measured by STEM-EDX the evolution of the concentrations during the growth of intragranular $\alpha$ plates at an intermediate temperature of $610^{\circ} \mathrm{C}$.

Table 1: Nominal chemical composition and $\beta$-transus temperature of the Ti-5553 alloy investigated.

\begin{tabular}{c|c|c|c|c|c|c|c|c|c}
\hline \hline Element & $\mathrm{Ti}$ & $\mathrm{Al}$ & $\mathrm{Mo}$ & $\mathrm{V}$ & $\mathrm{Cr}$ & $\mathrm{Fe}$ & $\mathrm{O}$ & $\mathrm{T}_{\beta}\left({ }^{\circ} \mathrm{C}\right)$ \\
wt.\% & Balance & 5.5 & 4.9 & 4.8 & 2.7 & 0.4 & 0.2 & $860 \pm 5$ \\
at.\% & Balance & 9.6 & 2.4 & 4.4 & 2.4 & 0.3 & 0.6 & \\
\hline \hline
\end{tabular}




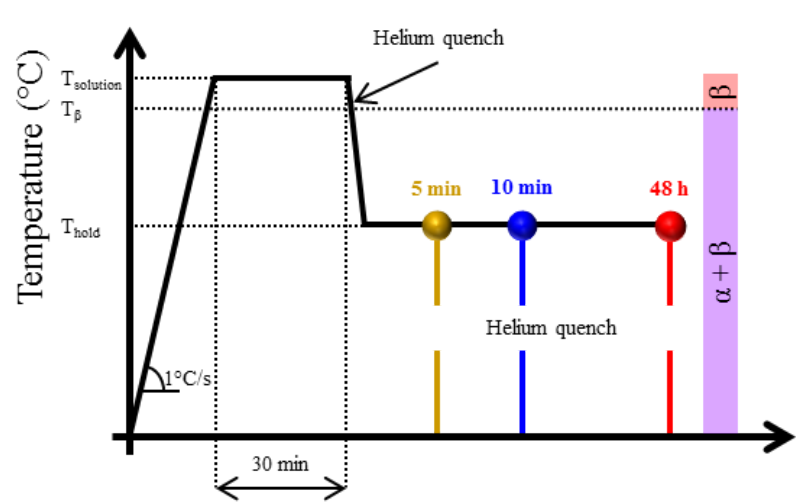

Time

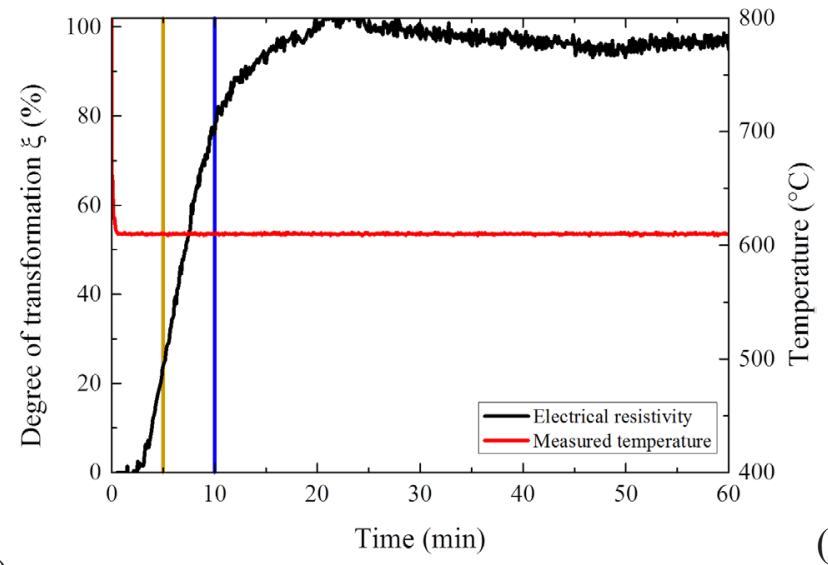

(b)

Figure 1. (a) Heat treatments. (b) Isothermal $\beta \rightarrow \alpha$ transformation kinetic at $610^{\circ} \mathrm{C}$ (Yellow and blue vertical lines indicate 5 min and 10 min respectively).

\section{Experimental procedure}

The experiments were carried out using Ti-5553 alloy, provided by Safran Landing Systems and elaborated by Timet. Its nominal chemical composition and $\beta$-transus temperature $\left(\mathrm{T}_{\beta}\right)$ are given in Table 1 . Cylindrical specimen ( $30 \mathrm{~mm}$ long, $3 \mathrm{~mm}$ in diameter) have undergone heat treatments sketched in Figure 1.a. First, they have been heated at $1{ }^{\circ} \mathrm{C} / \mathrm{s}$ up to $900^{\circ} \mathrm{C}$ and held for 30 min in the $\beta$ field. Then, they were quenched down to the $\alpha+\beta$ field and annealed at $610^{\circ} \mathrm{C}$ respectively for $5 \mathrm{~min}, 10 \mathrm{~min}$ and $48 \mathrm{~h}$. Finally, they were quenched to room temperature by blowing helium gas in order to freeze the microstructure and the solute distribution in the phases. To prevent high temperature oxidation, all experiments were carried out under secondary dynamic vacuum $\left(\approx 10^{-4}\right.$ mbar). These heat treatments were performed using an in-house device equipped with in-situ resistivity measurement to monitor the precipitation of $\alpha$ : indeed, the relative variation of the resistivity $\xi=\left(\rho-\rho_{0}\right) /\left(\rho_{\text {end }}-\rho_{0}\right)$, with $\rho_{\text {end }}$ and $\rho_{0}$ the resistivities at the end and at the beginning of the isothermal treatment, provides a way to quantify the progression of the transformation.

For the sample held at $610^{\circ} \mathrm{C}$ for $48 \mathrm{~h}, \xi$ is plotted versus time in Figure 1.b. The decomposition of $\beta$ starts after $\sim 2$ min. Then, the electrical resistivity increases until $\sim 25$ min and remains approximately constant, indicating that the transformation is completed: 5 min can safely be considered as the beginning of the decomposition of $\beta$, and $48 \mathrm{~h}$ sufficient to reach equilibrium.

All the microstructures were observed at room temperature and characterized using SEM, TEM and STEM. TEM thin foils were prepared using a dual-beam focused ion beam FEI Helios NanoLab ${ }^{\mathrm{TM}} 600 \mathrm{i}$ FEG instrument equipped with an Omniprobe ${ }^{\mathrm{TM}}$ using standard routines. TEM/STEM observations and measurements were performed using a probe corrected JEOL-ARM 200F Cold FEG operating at $200 \mathrm{kV}$, and equipped with a JEOL XFlash ${ }^{\circledR}$ silicon drift detector for energy dispersive X-ray spectrometry (EDX) analysis. Z contrast high-angle annular dark field (HAADF) images were recorded with 50 and 180 mrad inner and outer collection. For quantitative STEM-EDX analysis, we have carefully determined the specimen thickness and the Cliff-Lorimer $\mathrm{k}_{\mathrm{A} / \mathrm{B}}$ factors so as to avoid or minimize absorption and fluorescence effects. For each investigated foil, the local thickness was obtained by using energy filtered transmission electron microscopy (EFTEM) images with reference to [4]. For the selected conditions, a total inelastic scattering mean free path $\lambda$ was calculated to be $97.40 \mathrm{~nm}$. Following Cliff-Lorimer method [5], appropriate $\mathrm{k}_{\mathrm{A} / \mathrm{B}}$ standard was calculated for each alloying element using electron probe microanalysis measurements carried out on the $\beta$ metastable state.
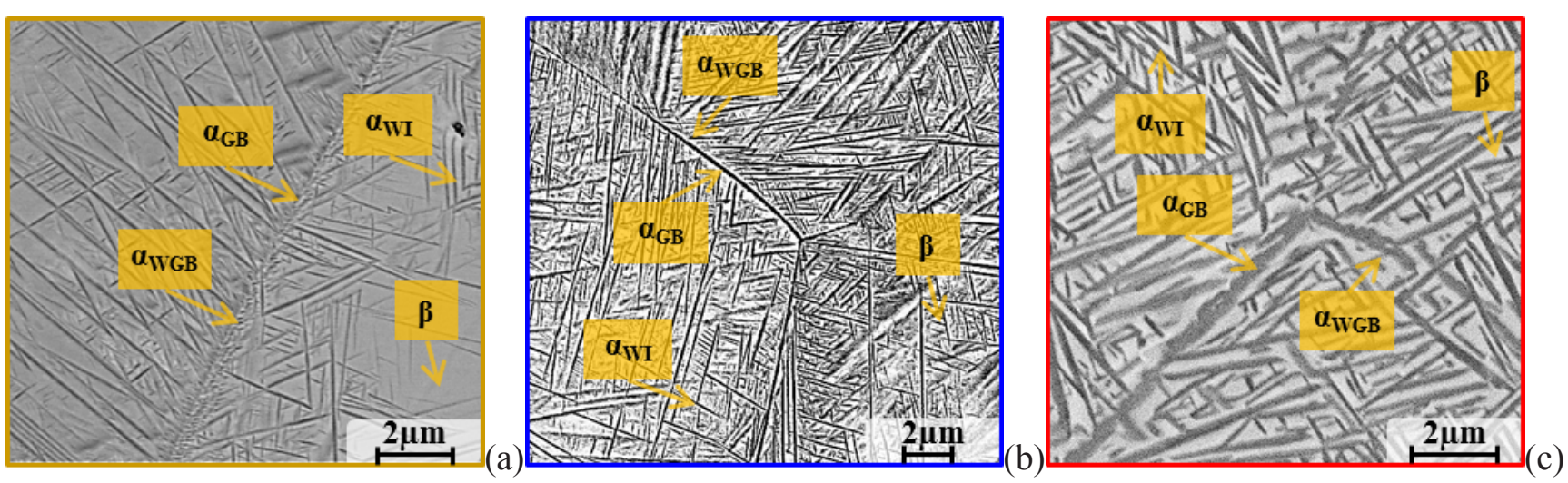

Figure 2. SEM observations (BSE) of microstructures obtained at $610^{\circ} \mathrm{C}$ for (a) $5 \mathrm{~min}$, (b) $10 \mathrm{~min}$, and (c) $48 \mathrm{~h}$ ( $\alpha$ in dark, $\beta$ in light). 


\section{3. $\underline{\text { Results }}$}

\section{a. Microstructures}

The microstructural evolution at $610^{\circ} \mathrm{C}$ is illustrated in Figure 2 with micrographs obtained at 5 min, 10 min and $48 \mathrm{~h}$. Different morphologies of $\alpha$ can be observed, already at 5 min:

- continuous layers of $\alpha$ along the prior $\beta / \beta$ grain boundaries $\left(\alpha_{\mathrm{GB}}\right)$;

- colonies of Widmanstätten parallel sideplates ( $\left.\alpha_{\mathrm{WGB}}\right)$, oriented from $\alpha_{\mathrm{GB}}$ precursors towards the center of $\beta$ grains;

- thin Widmanstätten intragranular precipitates $\left(\alpha_{\mathrm{WI}}\right)$ filling the $\beta$ matrix clear of $\alpha_{\mathrm{WGB}}$ colonies.

At 5 min, significant areas of the $\beta$ grains are still free of any $\alpha$ precipitates. As expected from the evolution of $\xi$ in Figure 1.b, the fraction of $\alpha$ increases with increasing holding time: there is no longer any free $\beta$ matrix at 10 min (Figure 2.b), whereas the $\alpha$ precipitates are larger after $48 \mathrm{~h}$ at $610^{\circ} \mathrm{C}$ (Figure 2.c).

Post-mortem measurements of $\alpha$ volume fraction by high-energy synchrotron X-ray diffraction (XRD) give $20 \%$ at $5 \mathrm{~min}, 48 \%$ at $10 \mathrm{~min}$, and $57 \%$ after $48 \mathrm{~h}$. This last value is close to $60 \%$ predicted at $610^{\circ} \mathrm{C}$ by Thermo-Calc and TTTI3 database [6]. This suggests that complete equilibrium has been achieved after $48 \mathrm{~h}$.

HAADF-STEM micrographs of microstructures at $5 \mathrm{~min}, 10 \mathrm{~min}$ and $48 \mathrm{~h}$ at $610^{\circ} \mathrm{C}$ are shown in Figure 3 . Similar locations have been selected in the different samples that display intragranular $\alpha_{\mathrm{WI}}$ precipitates. Considering different locations in a same sample, the plates are in average about 70,130 and $170 \mathrm{~nm}$ wide and 1.3, 1.5, $1.7 \mathrm{~mm}$ long at respectively $5 \mathrm{~min}, 10 \mathrm{~min}$, and $48 \mathrm{~h}$. This suggests that plate thickening is the major growth process explaining the increase in the $\alpha$ phase fraction, beside the nucleation of new plates occurring during the first $10 \mathrm{~min}$.

\section{b. Chemical partitioning}

To determine chemical partitioning, several STEM-EDX AA' line scans were carried out at different locations, crossing perpendicularly $\alpha_{W I}$ plates (yellow lines in Figure 3). The different AA' profiles in a same specimen were averaged: the average concentrations obtained on both sides of the $\alpha / \beta$ interfaces are plotted in Figure 4. Nominal concentrations and equilibrium concentrations predicted at $610^{\circ} \mathrm{C}$ by Thermo-Calc are also reported for comparison. As shown in Figure 4.a for $\alpha$, the average interfacial concentration in $\mathrm{Al}$ increases with increasing holding time from 10.4 to 12.6 at.\%. The concentrations of the $\beta$ stabilisers $\mathrm{Mo}, \mathrm{V}, \mathrm{Cr}$ and Fe, decrease slightly. The inverse is observed in Figure 4.b for $\beta$ : whereas the average concentration of $\mathrm{Al}$ decreases, significant increases are observed for $\mathrm{V}$ and Mo. These trends suggest that the composition of $\alpha / \beta$ interfaces evolves from nominal to equilibrium.
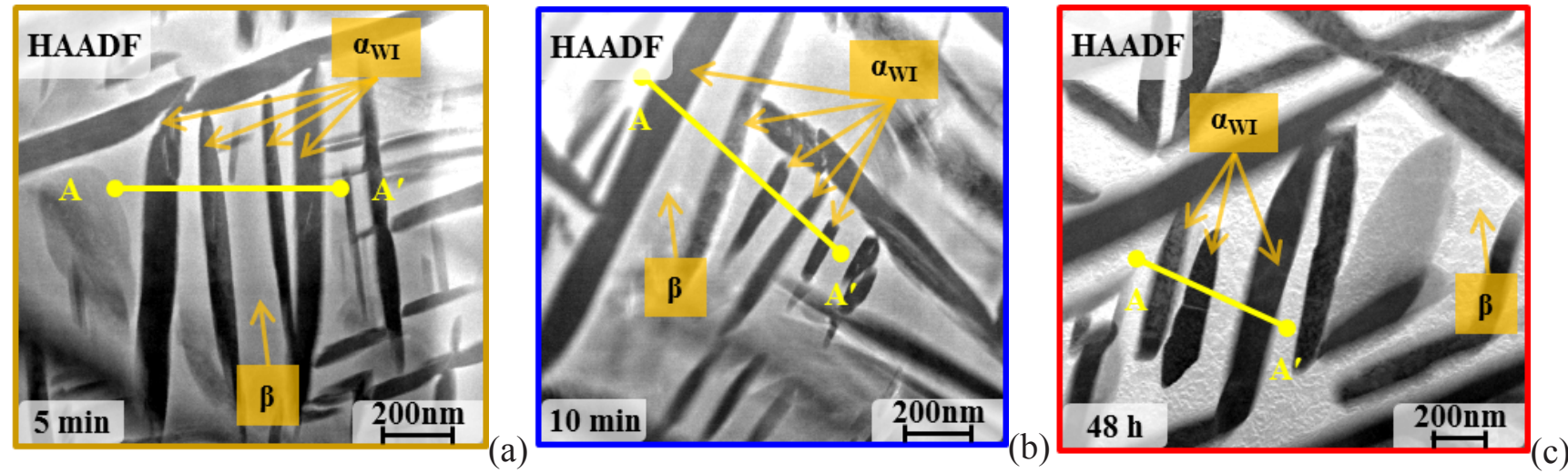

Figure 3. HAADF-STEM micrographs for samples held at $610^{\circ} \mathrm{C}$ for (a) $5 \mathrm{~min}$, (b) $10 \mathrm{~min}$ and (c) $48 \mathrm{~h}$. 


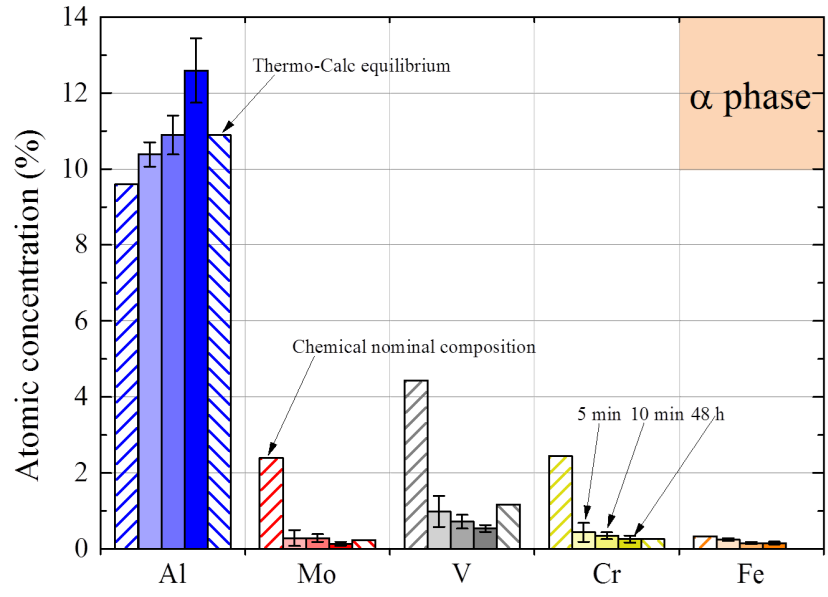

Solute elements in $\alpha$ phase $(\alpha / \beta$ interfaces $)$

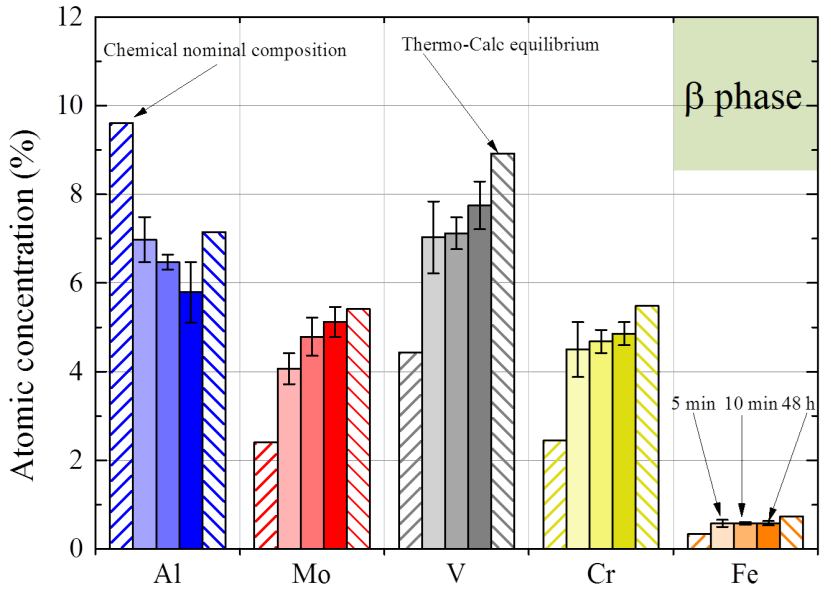

Solute elements in $\beta$ phase $(\alpha / \beta$ interfaces $)$

Figure 4. Evolution of the average chemical contents at $\alpha / \beta$ interfaces in (a) $\alpha$ and (b) $\beta$.

It should be emphasized that in-situ high-energy XRD experiments conducted at $610^{\circ} \mathrm{C}$ have shown that the average lattice parameter of $\beta$ decreases continuously as the transformation proceeds (i.e. increasing $\xi$ ) [7]. It was proposed that this decrease is linked to the increasing partitioning of alloying elements between the phases. Our measurements bring firm and clear support to this statement and suggest that thickening of the $\alpha$ plates proceeds in a mixed-mode manner, associating bulk diffusion and an interfacial sluggish process.

\section{Conclusion}

We have investigated the decomposition of the parent $\beta$ phase during the $\beta \rightarrow \alpha$ phase transformation occurring in $\beta$-metastable Ti5553 alloy at $610^{\circ} \mathrm{C}$, based on compositional characterizations, using advanced STEM-EDX technique. The quantitative chemical analysis provides new information about the transformation mechanism of titanium alloys at intermediate temperatures where the intragranular morphology is usually observed. Indeed, our measurements indicate that (i) $\alpha$ precipitates are likely to form with an initial low partitioning with respect to the supersaturated $\beta$ matrix, before (ii) becoming gradually rich in $\mathrm{Al}$ and poor in $\beta$ stabilisers $\mathrm{Mo}, \mathrm{V}, \mathrm{Cr}$ and Fe. Finally, after $48 \mathrm{~h}$ at $610^{\circ} \mathrm{C}$, the average chemical composition in both phases are close to the expected equilibrium compositions calculated with Thermo-Calc and TTTI3 database.

\section{Acknowledgements}

The authors gratefully acknowledge Safran Landing Systems for its financial support.

\section{$\underline{\text { References }}$}

[1] M. Enomoto and T. Yoshida, ISIJ International 31 (1991), pp. 767-774.

[2] Q. Chen, N. Ma, K. Wu and Y. Wang, Scripta Mater. 50 (2004), pp. 471-476.

[3] G. Charrier, M. Dehmas, M. Descoins, D. Mangelinck, E. Aeby-Gautier, B. Appolaire, S. Andrieu, F. Soniak, in: 13th World Conf. on Titanium, pp. 547-552.

[4] K. Iakoubovskii, K. Mitsuishi, Y. Nakayama and K. Furuya, Microscopy Research and Technique 71 (2008), pp. 626-631.

[5] G. Cliff and G.W. Lorimer, Journal of Microscopy 103 (1975), pp. 203-207.

[6] N. Saunders, Ti-DATA, a Thermodynamic Database for Calculation of phase Equilibria in multi-component Ti-based Alloys, Thermotech Ltd, Surrey Technology Centre, The Surrey Research Park, Guildford, Surrey GU2 5YG, U. K., http://www.thermotech.co.uk/databases.html\#Ti-DATA.

[7] A. Settefrati, Ph.D. thesis, UL (2012). 